\title{
Otto Richard Gottlieb (31/08/1920-20/06/2011)
}

por Maximus Taveira Santiago

Data de publicação na Web: 21 de Junho de 2011 Recebido em 21 de Junho de 2011 Aceito para publicação em 21 de Junho de 2011

Este texto é uma adaptação do discurso proferido, em dezembro de 2001, pelo Diretor do Centro de

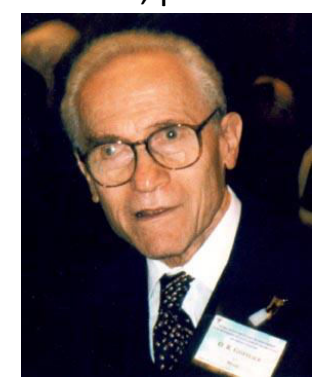

Ciências

Médicas da

Universidade

Federal

Fluminense,

Prof.

Maximus

Taveira

Santiago, na cerimônia de Outorga do Título de "Doutor Honoris Causa" concedido ao Prof. Otto Richard Gottlieb (figura 1) pela Universidade Federal Fluminense.

OTTO RICHARD GOTTLIEB nasceu em Brno, região da Morávia, Tchecoslováquia em 31/08/1920. Era a segunda cidade em importância da então República Tcheco-Eslovaca. Brno, terra natal de MENDEL, pai da moderna genética, do compositor Leo Janaceck e de Thomasz Masárik, primeiro presidente da República Tcheco-Eslovaca, localiza-se centralmente num quadrilátero geográfico imaginário que tem como referenciais Praga à Noroeste, a magnífica Cracóvia e a mística Czestochowa, ambas na Polônia, a Nordeste e ao Sul e Sudeste, respectivamente, as sublimes VIENA e BUDAPEST, antigas Capitais do Império AustroHúngaro, hoje capitais da ÁUSTRIA e da HUNGRIA.

Sua mãe nasceu em Petrópolis, Rio de Janeiro, o que deve ter influído na opção de OTTO GOTTLIEB pela nacionalidade brasileira, aos 21 anos. É interessante notar que Petrópolis é também a cidade escolhida por outro europeu com grande entusiasmo e carinho pelo Brasil, que foi STEFAN ZWEIG um dos grandes romancistas e humanistas europeus do período entre guerras e que lá faleceu no Carnaval de 1942.

Prof. OTTO fez toda sua carreira no país e cedo descobriu o amor pela flora nativa durante o trabalho na fabrica de óleos destinados à perfumaria do pai; gradua-se em Química Industrial (Universidade do Brasil, RJ, 1945) e após 10 anos na indústria, abraça a carreira acadêmica.

Da mesma forma que ZWEIG, GOTTLIEB fica fascinado pela diversidade da composição química da flora e fauna, nessa última fronteira biológica e de harmonia daquela época, que era - Brasil. Como resultado dessa fascinação se torna o pioneiro na introdução da fitoquímica, e concomitantemente da química orgânica moderna no Brasil.

Transferiu-se para a seção de fitoquímica do Instituto de Química Agrícola (1955-1963) do Ministério da Agricultura, no Rio de Janeiro e obteve os graus de Doutor e Livre Docente pela Universidade Federal Rural do Rio de Janeiro (1966) e de Professor Titular pela Universidade de Brasília (1964) e da Universidade de São Paulo (1975).

O Professor Otto Gottlieb, um dos mais importantes cientistas brasileiros, foi indicado para o Prêmio Nobel de Química de 1999, por seu trabalho pioneiro no estudo da composição das plantas realizado ao longo dos últimos 40 anos, trabalho esse que foi fundamental para revelar a enorme biodiversidade da flora brasileira, que é a mais rica do mundo.

Ao conhecer - realizando o sonho que ZWEIG não conseguiu e se apaixonar pela Amazônia, muito antes do meio ambiente tornar-se motivo de preocupação planetária, desenvolveu uma obra pioneira criando nova área da ciência que integra química e biologia e descobriu produtos naturais vegetais com grande importância para a medicina e, fundamentalmente, para a saúde.

Foi agraciado com várias premiações dentre as quais citamos o "Chemistry Award" conferido pela "The Third World Academy of Sciences" em $1991^{1} \mathrm{e}$ como reconhecimento pela "criatividade em bioquímica vegetal" foi agraciado com a concessão da mais prestigiosa conquista na área, que foi a outorga do "Prêmio Phytochemistry", da Pergamon Press, OXFORD, 1992 conferido a suas "destacadas contribuições para o nosso conhecimento da ecogeografia, evolução e sistemática de metabólitos secundários de plantas".

Ao longo desse quase meio século, criou cursos e grupos de pesquisa em algumas das Universidades e centros científicos mais importantes do Brasil, apresentando a seus alunos e colaboradores os métodos que 
desenvolveu para explicar a vida na Terra através da química, e nos últimos anos transferiu-se para a FIOCRUZ.

Mas o Professor Gottlieb acredita que tem pela frente muito trabalho; ouçamos, pois, algumas de suas reflexões:

“...sinto falta de liberdade e de maior apoio à pesquisa básica, que não pode ser dirigida por interesses econômicos imediatistas...";

"...aqui cientista é confundido com tecnologista; procura-se sempre uma aplicação imediata...";

"...Mas é preciso ter liberdade para conceber novas ideias; o cientista não pensa no presente; pensa no futuro...";

"...o Brasil só terá futuro se tiver uma ciência que pense nele; fazer ciência é essencial ao futuro de qualquer país..."; (ZWEIG descrevia o Brasil como o país do futuro);

"...no momento, tenho interesse em entender como o desequilíbrio ambiental pode provocar a ocorrência de novas doenças e trazer de volta outras consideradas erradicadas, como a malária...";

"...na verdade, isso faz parte de um projeto maior ligado á compreensão da biodiversidade brasileira, o de criar modelos numéricos que permitam prever interações ambientais..."

"...o Brasil constitui um modelo ambiental para o mundo..."

"...temos em mãos uma tarefa absolutamente fantástica; pois não sabemos nada sobre a composição química de 99\% da flora brasileira. E o Brasil é o país mais rico do mundo em plantas superiores, têm 55 mil espécies e pode ter ainda muitas outras ainda desconhecidas..."

"... minha maior satisfação foi ter ajudado a despertar esse país para as maravilhas que possui..."; (ZWEIG, recorda a alegria que dele se apoderou, verdadeira ebriedade de beleza e gozo que excitava os sentidos estimulava os nervos $e$ dilatava o coração, ... por mais que eu visse, ainda queria ver mais).;

"...espero ter forças para continuar a transmitir o que aprendi. Tive a oportunidade de mostrar a enorme riqueza química das plantas brasileiras e de chamar a atenção para o estudo da química integrada à biologia, que possibilitou a descoberta de produtos naturais importantes".

"...fico triste ao ver que até hoje o Brasil, o país mais rico do mundo em plantas, ainda não dá a devida importância ao assunto. Ainda não há nenhuma iniciativa significativa a esse respeito; é preciso mudar a forma de financiamento de pesquisas...";

"...fala-se o tempo todo em biopirataria, mas não se faz nada. O financiamento para pesquisas nessa área é ridículo...";

"...sou completamente contra a biopirataria, mas é difícil imaginar que a comunidade internacional vai ficar sentada esperando que um dia o Brasil decida finalmente explorar seus próprios recursos; durante muito anos, fez-se enorme pouco caso do assunto..."

"...é comum ter uma visão reducionista da biodiversidade, tentando entendê-la por um só ângulo; a natureza é dinâmica $e$ precisa ser encarada de forma ampla, holística..."

Coerentemente com tais pensamentos avança nas pesquisas investigando a elucidação estrutural de várias categorias novas de produtos naturais, que foram sempre seguidos pela descrição de alguns compostos especiais, como no caso do nitrofeniletano e de sua degradação a ácido cianídrico, de neoflavonoides e de sua biogênese, e das neolignanas e de seus rearranjos moleculares e que se constituem hoje, numa nova classe de substâncias antiinflamatórias.

Seu interesse principal em breve focalizou o desenvolvimento de uma linguagem interdisciplinar químico-biológica e os resultados obtidos levaram ao aprofundamento da compreensão dos padrões e dos mecanismos do funcionamento da natureza direcionando o interesse principal das pesquisas, que em breve focalizavam o desenvolvimento de uma linguagem interdisciplinar químico-biológica para a racionalização da evolução, sistemática e ecologia vegetais.

Para essa finalidade o Prof. Gottlieb e seu grupo desenvolveram métodos originais de fitoquímica e biodiversidade quantitativas, originalmente resumidas num livro intitulado Micromolecular Evolution, Systematics and Ecology, an Essay into a Novel Botanical Discipline, publicado pela Springer (1982) e utilizados por seu grupo para esclarecer questões de evolução, classificação e ecologia.

Nos anos seguintes, todos os três assuntos foram vastamente elaborados com a finalidade de racionalizar a busca de princípios ativos no reino vegetal, mapear e quantificar biodiversidade, unindo aspectos ecogeográficos, morfológicos e metabólicos dos organismos, que levaram ao aprofundamento da compreensão dos padrões e dos mecanismos do funcionamento da natureza.

Sua obra científica $\quad(700$ publicações científicas em livros e revistas especializadas, ${ }^{2} \quad 2$ patentes, 5 livros, 618 Conferências, sendo que 436 no Brasil e 182 em 26 outros países e 1114 comunicações em congressos científicos nacionais e internacionais) the permite lecionar cursos baseados em pesquisa própria. 
Recebeu ainda vários prêmios, entre os quais destacamos por suaexpressividade os dois primeiros, quando ainda aluno de graduação: Prêmio Freitas Machado, Escola Nacional de Química, Universidade do Brasil, 1943 e o Prêmio Shilling-Hillier, Escola Nacional de Química, Universidade do Brasil, 1945; a Medalha do Jubileu de Prata da SBPC, 1973; o Prêmio Fritz Feigl, CRQ $4{ }^{\text {a }}$ Região (SP, MT, RO); O Diploma de Honra ao Mérito, INPA, Manaus, 1978; a Medalha Ciência para Amazônia, CNPq, 1978; a Retorta de Ouro, Sindicato dos Químicos do Rio de Janeiro, 1980; o Prêmio Anísio Teixeira, Ministério da Educação, 1986; a Conferência RheinboldtHauptmann, IQ, da Universidade de São Paulo, 1990; o Prêmio Almirante Álvaro Alberto, MCT, 1990; a Ordem Nacional do Mérito Científico, classe Grã-Cruz, MCT, 1994.

Recebeu ainda a Medalha FIOCRUZ pela Ordem Nacional do Mérito Científico, 1994; o volume comemorativo do periódico "Archive for Organic Chemistry (ARKIVOC)", 2004; ${ }^{5}$ a Medalha Simão Mathias, Sociedade Brasileira de Química, 1997; a Retorta de Ouro, Sindicato dos Químicos do Rio de Janeiro, $1997^{6}$, entre outras honrarias.

Fundou e orientou grupos de pós-graduação e pesquisa em Química Orgânica e Bioorgânica em várias Instituições (Instituto de Química Agrícola, Rio de Janeiro; Universidade Federal de Minas
Gerais; Universidade Federal de Pernambuco; Universidade de Brasília; Universidade Federal Rural do Rio de Janeiro; Instituto Nacional de Pesquisas da Amazônia, Manaus; Instituto de Química da Universidade de São Paulo; Fundação Instituto Oswaldo Cruz, Rio de Janeiro) e já formou 119 mestres doutores.

Ministrou cursos de pósgraduação em Química Orgânica em muitas Instituições de Ensino no país; integrou o grupo de trabalho responsável por Pesquisas sobre Plantas Medicinais Brasileiras, da Central de

Medicamentos (CEME) e dirigiu o Curso Progressos de Ressonância Magnética Nuclear, patrocinado pela Organização dos Estados Americanos (OEA).

Presidiu, coordenou e organizou vários eventos nacionais e internacionais em sua área de conhecimento, entre eles o Simpósio "Biosynthetic Pathways and the Evolution of Higher Plants", realizado em Berlim; o Simpósio de Quimiotaxonomia do Congresso Latino-Americano de Botânica, realizado na Colômbia; o Simpósio Brasil-China de Química e Farmacologia de Produtos Naturais.

Durante cinco anos seguidos, ministrou os Cursos Especiais de Química Orgânica na Universidade Federal Rural do Rio de Janeiro e anualmente desde 1978 coordena as Reuniões Anuais de Evolução, Sistemática e Ecologia Micromoleculares (RESEM) realizadas em Instituições brasileiras e que se realiza na Universidade Federal Fluminense, pela terceira vez. Presidiu o $22^{\circ}$ International Symposium on the Chemistry of Natural Products, IUPAC, realizado na Universidade Federal de São Carlos, São Paulo, Brasil em setembro de 2000.

O Professor Gottlieb considera que, no final do século $X X$, a compreensão dos mecanismos da natureza é de importância essencial para o futuro da vida no planeta Terra e constitui o desafio mais significativo para os cientistas que vivem nas últimas fronteiras biológicas.

Nada revela melhor o impacto do seu trabalho do que a citação no diploma conferido pela Universidade de Hamburgo, ao outorgar-lhe o título de "Doutor Honoris Causa", em 1988: "A Universidade visa honrar o cientista e mestre reconhecido mundialmente que, através de sua sintese interdisciplinar da química de plantas e da investigação em evolução botânica, abriu novos caminhos para a ciência."

Como as origens do Prof. Gottlieb, que remontam ao BRASIL pelo lado materno e à Morávia, na Tcheco-eslováquia, pelo lado paterno, de forma assemelhada às origens paternas de Stefan Zweig, que tem suas origens, pelo lado materno, provenientes de Ancona, Itália.

O relato de Zweig do novo país que conheceu, numa casual visita a caminho de Buenos Aires, cunhou uma expressão definitiva do país, fruto da forte impressão que nele o Brasil deixou, tão intensa que se tornaria o título de um de seus últimos livros: "o país do futuro".

Definitivamente encantado, assim como Gottlieb, Zweig em sua segunda viagem ao Brasil passa seis meses explorando, tanto o litoral quanto o interior acessível, à época. 
Nesse ponto peço licença ao homenageado e aos presentes para tentar completar a ponte que venho tentando fazer, desde o início dessa Sessão Solene de outorga ao Prof. Otto Richard Gottlieb do Título de "Doutor Honoris Causa", entre esses dois seres humanos, morávios de raiz e que em suas épocas e formas de atuação, identificaram as reais potencialidades desse grande país, disponíveis para que exerça seu papel como ator qualificado na cena mundial .

Cada qual a seu modo, empenharam-se em mostrar e propagar ao mundo "civilizado" a existência de um país fantástico, quase que constituindo uma nova civilização da qual o próprio Zweig nos fala no seu "Brasil País do Futuro".

Esse tema caro a tantos brasileiros, dentre os quais destacamos Anísio Teixeira, Paulo Freire, Darcy Ribeiro, Barbosa Lima Sobrinho e Milton Santos, entres outros milhares de desconhecidos que procuram pensar 0 desenvolvimento desse país de forma menos desigual e que alicerce a construção de uma sociedade mais justa e fraterna, sem a presença de tantas e tão perversas desigualdades.

Todos, sem exceção, colocam em evidência a necessidade urgente de educarmos nosso povo.

Vale nos perdermos um pouco acompanhando a óptica de Zweig, esse refinado vienense, cidadão do mundo e na ocasião um dos autores mais publicados e traduzidos em todo o mundo.

Ouçamo-lo em sua introdução de "Brasil País do Futuro" :

"Quando no ano de 1936 devia partir para Buenos Aires a fim de tomar parte no congresso do Pen Club, recebi convite para, aproveitando essa viagem, visitar o Brasil. Imaginava que fosse o Brasil uma república qualquer das da América do Sul, que não distinguimos bem umas das outras, com clima quente, insalubre, com condições políticas de intranquilidade e finanças arruinadas, mal administrada e só parcialmente civilizada nas cidades marítimas, mas com bela paisagem e com muitas possibilidades não aproveitadas país, portanto, para emigrados ou colonos e, de modo nenhum, país do qual se pudesse esperar estímulo para o espírito. Uma visita de dez dias a tal país pareciame suficiente para quem não é geógrafo, colecionador de borboletas, caçador, sporstman ou negociante. Demorarei lá oito ou dez dias e depois regressarei depressa, assim pensei, $e$ não me envergonho de confessar esse meu modo insensato de pensar...

Deu-se então $\quad a$ minha chegada ao Rio, que me causou uma das mais fortes impressões de minha

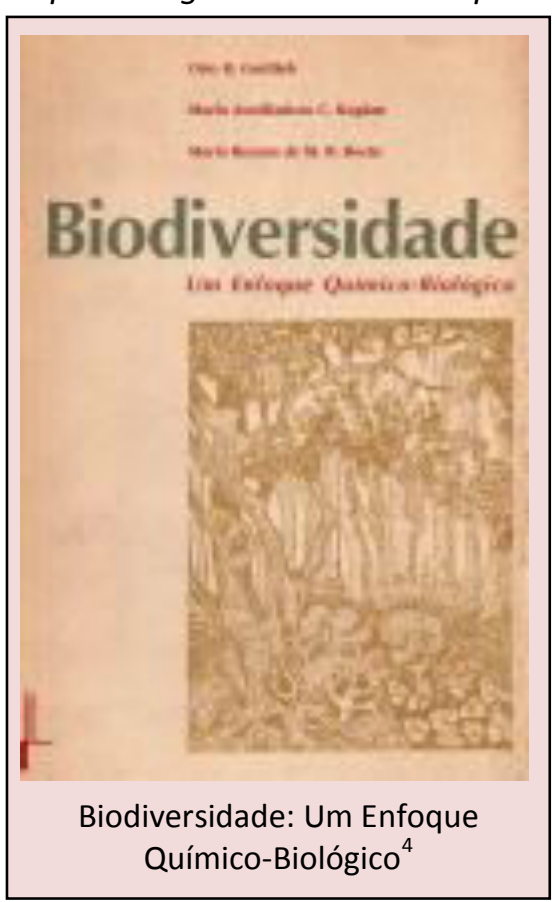

vida. Fiquei fascinado e, ao mesmo tempo, comovido, pois se me deparou, não só uma das mais magníficas paisagens do mundo, nesta combinação sem igual de mar e montanha, cidade $e$ natureza tropical, mas também uma espécie inteiramente nova de civilização..., aqui havia arrojo $e$ grandiosidade em todas as coisas novas e, ao mesmo tempo, uma civilização antiga ainda conservada de modo muito feliz, graças à distância...

Percebi que havia lançado um olhar para o futuro do mundo."
Continua às pags. $84-85$, ao discorrer sobre nossa potencialidade econômica:

"O descobrimento do ouro na província de Minas Gerais é um acontecimento mundial que influencia de modo decisivo toda a situação econômica da época; segundo afirma Werner Sombart, o desenvolvimento capitalista $e$ industrial da Europa, no fim do século dezoito, teria sido impossível sem a penetração impetuosa e estimulante do ouro brasileiro nas artérias da vida econômica europeia, que imediatamente pulsaram com maior rapidez.

A quantidade de ouro que o Brasil, esse país até então despercebido, lança de repente no mercado, é para aquela época quase inimaginável.

Segundo os cálculos de Roberto Simonsen, que merecem confiança, num vale de Minas Gerais naquele meio século se extraiu mais ouro do que todo o que foi extraído no resto da América até $o$ descobrimento das minas da Califórnia, em 1852.

O ouro do Peru e do México, que lançou o século dezesseis num acesso de loucura e duplicou e triplicou o valor monetário de todas as coisas lo que Montesquieu tão grandiosamente descreveu em seu célebre estudo "Les Richesses de l'Espagne"), representa apenas um quinto, ou talvez um décimo do que a colônia durante tanto tempo menosprezada fornece à sua metrópole.

Lisboa, que estava em ruínas, foi reconstruída com esse ouro, o colossal Convento de Mafra foi 
edificado com o "quinto" que por lei se tinha que dar ao rei.

$O$ súbito florescimento $d a$ indústria inglesa só pode dar-se de modo tão grandioso graças a esse adubo amarelo e o comércio e a transformação da Europa, graças a esse súbito afluxo adquiriram um impulso rápido. Durante um período curto, durante cinquenta anos, o Brasil é a tesouraria do Velho Mundo e a colônia mais poderosa e mais invejada que uma nação europeia possui.

Por um instante, quer parecer que o sonho dos conquistadores se realizou $e$ que se descobriu o lendário Eldorado".

O Eldorado de que fala Zweig é o descrito e desvendado por Gottlieb: O Eldorado de paz e prosperidade gerados pela empreendedora ação exploratória de nossos recursos provenientes da biodiversidade e da riqueza de nosso solo e águas, que podem decisivamente contribuir para nos tirar da condição de servos - uma das muitas possibilidades apontadas por Zweig -, novos escravos de uma nova/velha ordem colonialista onde só aparecemos como fornecedores de matérias-primas, que retornam para nosso consumo como produtos "altamente sofisticados".

Tivesse o governo respeito por seus cidadãos e alguma sensibilidade a nível epidérmico veria que gerações de brasileiros estão fadados à escravidão, em seus variados, dissimulados e sedutores modos de apresentação, pois assistimos a encenação do verdadeiro "Show de Truman", ao vivo e a cores, não com foco na vida diária de um ator, mas com toda uma Nação atuando como ator coadjuvante, indefesa frente a massificação que lhe é imposta diuturnamente pela mídia televisiva, que invade nossas casas tentando e por vezes conseguindo, impor seus padrões de ética, moralidade e comportamento.

O caldeirão cultural que entrou em ebulição com o fim do império Austro-Húngaro no eclodir do século $\mathrm{XX}$, agitou fisicamente os ares vienenses $e$ inconscientemente

os

pensamentos dos habitantes daquele mundo de então, inclusive os daquele quadrilátero geográfico imaginário, influenciando entre outros tantos Zweig, Hoffmanstall, Freud, Thomas Mann, Heinrich Mann, Arthur Schnitzler.

A ebulição alimentou a curiosidade das gerações seguintes, o que propiciou a Gottlieb levantar o véu das nossas potencialidades como Nação, permitindo através da simplicidade de suas explanações a formação de grande número de seguidores, marca registrada dos grandes Homens; obrigou-nos a enxergar o quanto de nossa riqueza é expropriada, com a contribuição decisiva, pelo conluio espúrio de nossas elites, para o estado das misérias e desgraças que são encontradas em qualquer lugar deste belo e imenso país.

"Pensamos muito mas sentimos pouco; há necessidade de mais espírito humanitário do que de mecanização; mais do que inteligência, precisamos de amabilidade e gentileza.

Sem essas qualidades, a vida não será mais do que violência e tudo se perderá."

O autor destas curtas frases é o mais sublime dos palhaços, que o mundo já conheceu: Charles Chaplin, que demonstrou com simplicidade comovente e picaresca, que o rei estava nu.

O "rei" era Adolf Hitler, entronizado no poder por acordos espúrios entre a burguesia da época e alguns partidos políticos, nacionais e estrangeiros, que o viam como um "mal menor ou mesmo necessário" para barrar o "perigo do avanço

do bolchevismo".

Tornou-se legitimado arauto e principal propagador de uma política cujo objetivo final era disseminar o pensamento único pela Europa e pelo mundo, pregando $o$ extermínio das minorias e dissidentes, como hoje o fazem as televisões, porta-vozes dos sistemas políticos que as sustentam com as vastíssimas verbas da propaganda, ao reportarem as "guerras de precisão cirúrgica" pelo mundo afora e que no Brasil atuam sob o olhar leniente dos governantes.

É sabido o que esse conluio propiciou, e é importante que o relembremos, sempre, para que as gerações seguintes dele não se esqueçam, nem se deixem iludir.

Vaclav Havel, poeta, pensador, teatrólogo tcheco, um dos líderes da chamada Revolução de Veludo de 1977 e que terminou por alcançar a Presidência da Tchecoeslováquia e depois da República Tcheca, cita num de seus livros "Entrevista a Distância" - o filósofo Jan Patocka, morto em 1977 depois de interrogado pelo serviço de segurança do estado.

Entre vários de seus pensamentos, pontuava Patocka: "a verdadeira prova de um homem não consiste na maneira em que realiza o que decidiu, mas na maneira em que desempenha o papel que o destino lhe reservou".

Vivemos uma era de definições; de insubmissão contra a injustiça e a opressão de bilhões de seres humanos "excluídos do mercado", eufemismo cunhado na era do politicamente correto para definir miseráveis.

As descobertas propiciadas pelas linhas de pesquisa desenvolvidas pelo Prof. Otto Gottlieb e por muitos de seus discípulos e seguidores, nos permite afirmar que é urgente que definamos nosso rumo como 
Nação, para que possamos romper os elos dessa cadeia perversa que nos prendem ao subdesenvolvimento.

Precisamos optar entre a eficiência de produtor e exportador de bens de baixo valor agregado, e continuarmos contemplando a uns poucos que se saciam escandalosamente, ou descobrir e cultivar produtos que detêm maior valor agregado, para neles focarmos as fontes de maior competitividade e de maior consistência como fontes de nossa receita externa, para que possamos gerar mais empregos no País, e não no exterior, ter mais brasileiros comendo condignamente, e não tão somente exportarmos soja para a engorda de porcos; mais crianças nas escolas, melhores escolas, prioridade de investimento na melhora dos serviços públicos, menor incidência de doenças originárias do descaso e da falta de prioridade dadas à Saúde e à Educação, em favor da gastança desbragada com os juros elevados para amortizar uma dívida que, já fartamente se provou, foi muitas vezes paga.

Basta de fazer o bolo crescer; pois quando ele cresce 0 suficiente, dele não comemos!

É chegada a hora de reagirmos e a outorga deste título é o nosso muito obrigado Professor OTTO, por nos ajudar a ver o que todos lá fora já viram e querem para si.

De tal relevância é esse assunto que foi tema central nos debates entre os Césares da nova Roma (que por vezes atende por seu nome de batismo: Washington): qual a definição de integridade territorial, em especial da Amazônia?

Definiram-na, cinicamente, como "território do mundo".

Muito Obrigado, Prof. Otto Richard Gottlieb, por sua lição de vida e pela descoberta das muitas possibilidades de que dispomos e que não são aproveitadas como estímulo para o espírito, como dizia Stefan Zweig.

Obrigado por apontar e nos fazer conscientes, permitindo que lutemos por este país fantástico e ao mesmo tempo tão injusto, chamado BRASIL e que já não é mais tão somente o país do futuro, mas também o país do presente, e que necessita de urgentes reformulações sociais, para que as potencialidades e riquezas descritas por Zweig e desvendadas em seus trabalhos, Prof. Otto, não continuem sendo apropriados por uma plutocracia, que mantém na miséria e no desespero milhões de irmãos brasileiros.

Quando um país trata os problemas da escandalosa concentração da terra, usada como mecanismo de riqueza e investimento, como caso de polícia e não como um dos escândalos sociais mais evidentes da brutal concentração de renda no País, algo precisa, urgentemente, ser mudado. Pois então, o mudemos.

Obrigado, Prof. Otto.

PS. O Prof. Otto R. Gottlieb faleceu em 20/06/2011 aos 90 anos. $^{7}$
Foto do Prof. Otto R. Gottlieb foi cedida pela Academia Brasileira de Ciências

Referências bibliográficas

em:

Sítio da TWAS. Disponível

$<$ http://twas.ictp.it/prog/prizes/re cipients-of-twas-awards-

prizes\#1991>. Acesso em: 21 junho 2011.

2 Sítio do canal da ciência. Disponível em: $<$ http://www.canalciencia.ibict.br/ notaveis/resumo.php?id=73>.

Acesso em: 21 junho 2011.

3 Seidl, P. R.; Gottlieb, O. R.; Kaplan, M. A. C.; ACS Symposium Series 588, Manaus, 1995. [Link]

$4 \quad$ Gottlieb, O. R.; Kaplan, M. A. C.; Borin, M. R. de M. B.; Biodiversidade: Um Enfoque Químico-Biológico, Editora UFRJ: Rio de Janeiro, 1996.

5 Bolzani, V. S.; Cragg, G. M. Arkivoc 2004, Part VI, 1. [Link]

$6 \quad$ Sítio do Conselho Regional de Química - IV Região. Disponível em:

$<$ http://www.crq4.org.br/default.p $h p$ ?p=texto.php\&c=premio fritz $f$ eigl>. Acesso em: 21 junho 2011. $7 \quad$ Sítio do Jornal O Globo. Disponível em: <http://oglobo.globo.com/ciencia/ mat/2011/06/20/morre-cientistaotto-gottlieb-aos-91-anos924723966.asp\#ixzz1Puc1WNyS>. Acesso em: 21 junho 2011.

Universidade Federal Fluminense, Centro de Ciências Médicas, Faculdade de Medicina, Rua Marques do Paraná, 303, Centro, 24000-303, Niterói-RJ, Brasil.

$M$ maximuscoliseum@gmail.com

DOI: $10.5935 / 1984-6835.20110026$ 